\title{
The Sustainability of Urban Planning and Construction
}

\author{
Liu Hong \\ The Department of Public Administration \\ the Yunnan University of Finances and Economics \\ Kunming, China \\ 06liuhong@sina.com
}

\begin{abstract}
: although the rapid economic development is so fast, the per capital resources of is limited, population growth, and there is also an increasing pressure on the ecological environment in the city, urban situation faces more severe competition, how to determine the nature of the city, deciders need to consider the size and direction of development, the path of sustainable development and the current problems. We usually achieve in a given period of economic and social development goals of the city, to determine the nature of the city, the size and direction of development, rational use of urban land, coordinating the deployment of integrated urban space layout and the construction and the specific arrangements referred to city planning.
\end{abstract}

Key words: sustainability; urban plan; construction

I. THE DEFINITION OF AN URBAN PLANNING

Urban planning is to achieve a certain period of economic and social development goals of a city, which determines the nature, size and direction of development, rational use of urban land, coordinating comprehensive and specific arrangements for the deployment of urban space layout and the construction done. Urban planning is the fundamental basis for the construction of the city and the management of the city, which consists of two aspects, namely, urban planning and urban construction.

The first one is urban planning, which refers to the overall urban development plan in accordance with the appropriate geographical, cultural conditions, economic development and other cities of the objective conditions, to coordinate all aspects of urban development, and further to the spatial layout of the city, land use, infrastructure, etc. Another aspect is urban construction. The government body is based on the content of planning ${ }^{1}$. The plans like to achieve energy infrastructure, transport, communications, information networks, landscaping and environmental protection are all urban construction.

\section{The Significance of Sustainable Urban Planning}

Domestic and international experience has shown that the construction of a city depends first on the scientific and

\footnotetext{
1 Dodson J. The 'infrastructure turn'in Australian metropolitan spatial planning $[\mathrm{J}]$. International planning studies, 2009, 14(2): $109-123$
}

rational urban planning ${ }^{2}$. We must first scientifically forecasting and planning through clear the city, the size, direction and development pattern, under the guidance of planning and regulation, there are steps to achieve the goal of urban development stages. As the complexity of the urban social and economic activities and urban expansion of the scale of the whole system functions, urban planning requirements continue to increase, the importance of urban planning has become more prominent.

As the economy continues to develop, the demanding of urban living environment is increasing. Sustainable urban planning not only refers to the level of sustainable technologies, and more importantly, is the culturally and psychologically sustainable environment. Scientific urban planning is to enhance the overall function of the city is the soul of urban development. A scientific master plan itself is the greatest resources and wealth. Modern urban planning is no longer confined to the mechanical construction of urban space layout and materials. But to urban development and the combination of natural ecological principles of sustainable development and greater integration into the urban planning among the urban environment, construction, protection, regulation and other issues should be fully reflected in the plan, and implement in Each level of planning every aspect. Taking the different time and space into account, the rational allocation of resources meets the needs of the present, instead of the ability of future generations to meet their own needs constitute a hazard ${ }^{3}$.

\section{III.CITY PLANNING PROBLEM FROM THE PERSPECTIVE OF SUSTAINABLE DEVELOPMENT}

\section{A.The Scale of the City}

The reality is that the scale of city is not calculated the scientific and reasonable conclusions, but decided by officials, which has certain scientific basis, but also there is no lack of

\footnotetext{
2 Hall, Peter, and Ulrich Pfeiffer. Urban future 21: a global agenda for twenty-first century cities. Routledge, 2013.

3 Buyya, Rajkumar, Anton Beloglazov, and Jemal Abawajy.

"Energy-efficient management of data center resources for cloud computing: a vision, architectural elements, and open challenges." arXiv preprint arXiv:1006.0308 (2010).
} 
subjective components ${ }^{4}$. Now the country towns above the entire town after ten years may exceed the national population. Out of control the scale of urban population estimates, urban planning control to determine the urban planning area, all aspects of the urban material space layout, urban settings and co-ordination arrangements of natural resources caused great waste, but also left a lot of regret for the benign development of urban.

\section{B. The Format Of The City}

Many designers present a lot of urban planning and always hope to achieve a breakthrough, in the form of some meaning like "dragon and phoenix", "erlongxizhu", "Kowloon water", "Good luck and happiness to you!" and so on, draw a forced analogy ideas. This pursuit of pure surface effects caters to some social pursuits, making the city state creation into a misunderstanding 5 .

\section{The Ecological Problems of the City}

Ecological city construction is one of the main goals of the pursuit of many of today's city managers and planners have attached great importance to. But from the planning practice, many of leaders understand the concept of the ecological city only stay in the big are water and greening system arrangement level understanding of this shallow level, ecological city planning is difficult to see the real examples.

Ecological city is an economic developed, social prosperity, ecological protection three to maintain a high degree of harmony, nature and technology to achieve the full integration of city, environment clean, beautiful, comfortable, so as to maximize the creativity and productivity of the people, and is conducive to the artificial composite system to improve the city Wen Mingcheng degree stability, sustained and coordinated development, the. Study on the complexity of the problem is also very comprehensive. Urban planning as a key link, to a comprehensive analysis of various factors, the system considers all aspects of the problem, set the research achievements of various subjects.

\section{REASONS OF THE CITY PLANNING FAILED TO ACHIEVE SUSTAINABILITY}

\section{A. Lack of A Clear City Positioning}

when occupied city development scale of resources and the environment more than the supporting capacity of the base itself, resources will be unable to supply development difficulty, this poses a threat to the whole city space system, landscape system and environment system, not only lead to the planning and layout of confusion, also make the planning become meaningless. The wrong city location and scale plan will prevent the creatation of the city construction from the reality, and the beautiful design can finally realize.

\section{B.Lack of Design of City Public Space.}

4 Di Martino, Adriana, et al. "The autism brain imaging data exchange: towards a large-scale evaluation of the intrinsic brain architecture in autism."Molecular psychiatry 19.6 (2014): 659-667.

5 Hirsch F. Social limits to growth[M]. Routledge, 2005.
Designers often stand in a higher angle integrated control, sometimes ignoring open space atmosphere and the perspective of citizens feel the effects of social as well as economic factors, coupled with government agencies and developers added, resulting in the real city planning for human factors neglected. And reasonable city scale of development must be based on a clear positioning of the nature of the city ${ }^{6}$, on the development of state city economy to have a rational and scientific ideas and reasonable calculation on bearing city development on the basis of natural resources.

\section{C.Lack of Ecological And Environmental Protection.}

Although the city planning set up environmental protection badge, more more and focused on environmental remediation planning, however this is only to play the role of less effective remedy. In addition, the planning layout did not fully consider the environmental factors of city planning designers; environmental protection ability is weak, after the implementation of the planning of the environmental influence of uncertainty leads to the lack of government control, a lot of city construction system on the environment caused great destruction. A lot of natural ecological conditions, historical and cultural city geography, customs are different, but the city planning convergence caused by "Thousands of City Side", the loss of local characteristics. Especially in the city's historical context, the misunderstanding is often neglected or goes to the transformation and construction error, serious damage to the antique city $^{7}$. In addition, the natural characteristics is a city of natural features, often in city planning in the understanding is not enough, some of the city's forest, wetland was diverted, lost the natural, also lost the original ecological function.

\section{V.THE SUSTAINABLE DEVELOPMENT OF CITY PLANNING AND CONSTRUCTION}

The strategy of sustainable development as an important guiding ideology, it is to improve the science of city planning, with the realistic, affects the city's future development, it requires us to establish the following concept in city planning.

\section{A.Position The City And City Development In Science}

The overall positioning of city is an important step in the city long-term development objectives, and the nature of the scale, geographical environment, the development process of city industrial structure associated with each other, and the overall image of these are associated with the city are inseparable. The establishment of survey design and evaluation mechanism of perfect urban positioning caution needs, based on sufficient investigation and research, thorough masses $^{8}$, making the overall urban location and

\footnotetext{
6 Benford, Steve, et al. "The error of our ways: the experience of self-reported position in a location-based game." UbiComp 2004: Ubiquitous Computing. Springer Berlin Heidelberg, 2004. 70-87.

7 Kammen M. Mystic chords of memory: The transformation of tradition in American culture[M]. Vintage, 2011.

8 Barone, Tom, and Elliot W. Eisner, eds. Arts based research. Sage, 2011.
} 
history case, bold innovation at the same time not divorced from reality, such positioning to guide urban planning is truly meaningful, have realized the possible.

First of all, in the objective analysis and forecast the level of urbanization on the basis of future, rationally determine the scale of urban population and urban land scale; the construction of integrated conservation transportation system to save power as the center, the urban traffic system construction to the bus based. Reasonable industrial layout and construction of integrated area, which could reduce the freight volume ${ }^{9}$. To improve the efficiency of land use, and actively adjust land use structure and model of city, apartment type construction and urban center area. Building energy saving, raw material as the center of the industrial production system. Secondly, the planning and design should be guaranteed in the overall layout frame is relatively stable under the premise of leaving a certain elasticity and long-term development of the room, consider the possibility of partial adjustment according to the actual need of land.

\section{B. Deal With The Natural Ecological Environment Cautiously}

Sustainable urban planning should first of all in accordance with the laws of nature, in a cooperative and friendly attitude towards the environment, even if the designer for professional environmental knowledge know little should also treat the nature with respect to one of the most basic principle is not rude to take all unreasonable actions simply treat the environment. First of all, we should plan as a whole urban ecological system, before performing any acts require environmental and resource studies urban carrying capacity, to ensure a clear manifestation of concern for the environment in the planning, promote the sustainable development of resources and environment sustainable use and city.

Finally, in the planning and implementation of no matter from the angle of design and construction for further perspective $^{10}$, all need to pay attention to place making micro environment, perhaps less damage to transform than down some re construction, perhaps a tree several a piece of water will also increase with respect to the ecological balance, so that the needs of designers have a higher sense of mission and processing ability. Limiting the city production, life activities in the capacity of the environment within the allowed range, coordinating the relationship between man and nature, pay attention to the construction of green open space. The protection of wild animal and biological species, the delineation of protected areas of activity, biodiversity conservation, and coordinate the relationship between human and biological. Pay attention to the social improvement of environmental quality; establish a fair and reasonable social order, coordinating the relations between people and people, improving the quality of the population and the degree of social civilization.

9 Lengauer, Thomas. Combinatorial algorithms for integrated circuit layout. Springer Science \& Business Media, 2012.

10 Wang, Liuping. Model predictive control system design and implementation using MATLAB ${ }^{\circledR}$. Springer Science \& Business Media, 2009.

\section{C.Pay Attention To Local Historical Context Features.}

The so-called the nation is the world, the planning and construction to be able to develop continuously, the premise that any development is to respect the history, therefore the protection of local historical context should be the primary consideration factors of any planning and design. The city's historical context includes not only the historic building, the old city also includes the special texture, neighborhood patterns, habits and so on, so it is more important to human history carrier deep utilization and city culture connotation extension ${ }^{11}$. Once again, the protection of local characteristics of the way does not mean by protecting single Museum, take city protective renovation activities determine the construction level of protection of cultural relics, suit one's measures to local conditions to determine the construction planning mode of protection of historical and cultural relics of different, such as combining the pedestrian area construction and protection of historical buildings, updated to meet the modern requirements for internal use, outside to keep old traditional architectural style,

Finally, the characteristic of the city that can best reflect the details of life, should the regional characteristics of detailed study plan, respect local local materials and colors. We should extract details from the local houses, city, street in the old city as a design element, and then convert to the use of the planning and design of new town on. They'll give the planning and city design brings strong characteristics of the local culture, thus bringing should be identifiable as the city.

\section{Strengthen Planning And Executive Ability}

We say that the sustainability of the city planning, although this construction of environment whether respect for history respect for cultural society, whether can the long-term development to create a harmonious social environment, and the key factors of all these efforts to explore and realize the is planning is able to smoothly perform as expected, if the lack of execution, then planning and careful considerations in science also empty talk can not play its due role, that is the real "unsustainable". From the angle of executive power, hand to determine the overall city planning, city planning and architectural design further need enough attention ${ }^{12}$ and respect for the overall planning, broad principles should not change; on the other hand, in the implementation process should not let the market rules and economic reasons too hindered planning execution, control need to have long-term vision, give full play to the guiding role of city planning control, realize the sustainable development of city space quality of environmental quality.

\section{Conclusion}

With the rapid development of social economy, the

11 Zhu, Jie, and Qianghua Duan. "Urban waterfront landscape cultural design studies." Remote Sensing, Environment and Transportation Engineering (RSETE), 2011 International Conference on. IEEE, 2011.

12 Kawamoto, Hiroaki, and Yoshiyuki Sankai. "Power assist method based on phase sequence and muscle force condition for HAL." Advanced Robotics19.7 (2005): 717-734. 
process of city more and more quickly, the status and role of the city has become increasingly prominent and important; the problem of sustainable development is not only a problem of ecological balance, sustainable utilization of environmental protection and resource, is more concerned about the social problems of city life quality of life. The introduction of sustainable development in city planning ideas, resources and environment system of city development and bearing capacity based on support, realize the coordinated development of city economy, society, population, resources, environment, to create a permanent eco city sustainable development for our local residents and descendants, is the times and social demand. Sustainable city planning and construction of the ultimate goal is to achieve the sustainable development of economy, the sustainable development of ecological environment, the sustainable development of the society and the state, to create a diverse harmonious city space.

\section{ACKNOWLEDGMENT}

On the completion of my thesis, I should like to express my deepest gratitude to all those people whose kindness and advice have made this work possible. I am greatly indebted to all the people who provide the help and gave me valuable instructions and has improved me in language. Their's effective advice, have kept the thesis in the right direction.

\section{REFERENCES}

[1] Barone, Tom, and Elliot W. Eisner, eds. Arts based research. Sage, 2011.

[2] Benford, Steve, et al. "The error of our ways: the experience of self-reported position in a location-based game." UbiComp 2004: Ubiquitous Computing. Springer Berlin Heidelberg, 2004. 70-87.

[3] Buyya, Rajkumar, Anton Beloglazov, and Jemal Abawajy. "Energy-efficient management of data center resources for cloud computing: a vision, architectural elements, and open challenges." arXiv preprint arXiv:1006.0308 (2010).

[4] Di Martino, Adriana, et al. "The autism brain imaging data exchange: towards a large-scale evaluation of the intrinsic brain architecture in autism."Molecular psychiatry 19.6 (2014): 659-667.

[5] Dodson J. The 'infrastructure turn' in Australian metropolitan spatial planning[J]. International planning studies, 2009, 14(2): 109-123

[6] Hall, Peter, and Ulrich Pfeiffer. Urban future 21: a global agenda for twenty-first century cities. Routledge, 2013.

[7] Hirsch F. Social limits to growth[M]. Routledge,2005.

[8] Kammen M. Mystic chords of memory: The transformation of tradition in American culture[M]. Vintage, 2011.

[9] Kawamoto, Hiroaki, and Yoshiyuki Sankai. "Power assist method based on phase sequence and muscle force condition for HAL." Advanced Robotics19.7 (2005): 717-734.

[10] Lengauer, Thomas. Combinatorial algorithms for integrated circuit layout. Springer Science \& Business Media, 2012.

[11] Wang, Liuping. Model predictive control system design and implementation using MATLAB ${ }^{8}$. Springer Science \& Business Media, 2009.

[12] 1Zhu, Jie, and Qianghua Duan. "Urban waterfront landscape cultural design studies." Remote Sensing, Environment and Transportation Engineering (RSETE), 2011 International Conference on. IEEE, 2011 